\title{
Cell penetrating peptide of sodium-iodide symporter effect on the I-131 radiotherapy on thyroid cancer
}

\author{
YI-XIANG FAN, ZHI-XIN LIANG, QING-ZHU LIU, HAN XIAO, KE-BIN LI and JI-ZHEN WU \\ Department of Nuclear Medicine, Second People's Hospital, Guangzhou, Guangdong 510317, P.R. China
}

Received June 12, 2015; Accepted July 22, 2016

DOI: $10.3892 /$ etm.2017.4079

\begin{abstract}
The aim of the present study was to clarify whether the cell penetrating peptide of sodium-iodide symporter (NIS) has an effect on the I-131 radiotherapy of thyroid cancer. Firstly, we combined the HIV-1 TAT peptide (a cell penetrating peptide, dTAT) and established a nanoparticle vector (dTAT NP) to study the delivery efficiency of this cell-penetrating strategy for tumor-targeted gene delivery. dTAT NP was transfected into cultured TPC-1 cells as a model to study the effects of I-131 radiotherapy on thyroid cancer. Reverse transcription-quantitative polymerase chain reaction and western blotting results showed that the mRNA and protein expression levels of NIS in the transfected TPC-1 cells were substantially higher than in the negative control cells. MTT and flow cytometric analyses demonstrated that the cell growth and apoptosis rates of the TPC-1 cells were significantly inhibited and activated, respectively, by treatment with dTAT NP. The results of DAPI staining showed that treatment with dTAT NP visibly increased the nuclear apoptosis rate of the TPC-1 cells. The effect of dTAT NP on TPC-1 cells was associated with the promotion of caspase-3 and downregulation of the PI3K/Akt signaling pathway. In summary, the present data provide a pre-clinical proof-of-concept for a novel gene delivery system that efficiently delivers NIS to the targeted cancer cells and presents a satisfactory efficacy. This approach may offer an effective strategy for improving thyroid cancer gene therapy.
\end{abstract}

\section{Introduction}

Thyroid cancer is the most common type of malignant tumor in the endocrine system. I-131 therapy has been used to treat differentiated thyroid cancer (DTC) (1). With demonstrable

Correspondence to: Dr Yi-Xiang Fan, Department of Nuclear Medicine, Second People's Hospital, 466 XinGang Middle Road, Guangzhou, Guangdong 510317, P.R. China

E-mail: xxyixiangfan@163.com

Key words: cell penetrating peptide of sodium-iodide symporter, thyroid cancer, caspase-3, phosphatase and tensin homolog/phosphoinositide 3-kinase/protein kinase B curative effects, this therapy has been recognized by clinical practice (2). However, the iodine uptake capacities of tumor nidi in $\sim 10 \%$ of patients are decreased or depleted entirely, which causes a reduction of treatment efficacy, resulting in a higher severity of anaplastic thyroid carcinoma (ATC) (3). Furthermore, with short median survival time and high mortality rates, these patients are less sensitive to various traditional therapies (for example, surgery and endocrinotherapy) (4).

DTC and ATC describe two possible endpoints of thyroid cancer (5). In fact, changes from DTC to ATC do not occur at once. As far as differentiated degrees, cell morphology and biological tumor behavior are concerned, there is a progression from DTC to ATC, i.e., from differentiated to poorly differentiated and then to dedifferentiated (6). The World Health Organization considers poorly differential thyroid carcinoma (PDTC) to be an intermediate between DTC and ATC (7).

With a length of $<10$ amino acids, cell-penetrating peptide is a micromolecular polypeptide that is able to penetrate through the cytomembrane into cytoplasm or the cell nucleus without damaging structures of the cell membrane (8). Studies in recent years have shown that cell-penetrating peptides may carry a series of substances with biological activities into living cells, including proteins, polypeptides, nucleic acids and oligonucleotides $(9,10)$. Hairpin-shaped cell-penetrating peptide is a recently identified transmembrane small peptide (11). Its hairpin structure can construct numerous protease sites, which may provide novel approaches for molecular targeted diagnosis and therapy.

As a glycoprotein, the $\mathrm{Na}^{+} / \mathrm{I}$-symporter (NIS), also known as an iodine pump, is located in the membrane of epithelial cells of the thyroid follicle (12). NIS participates in the iodine uptake process and plays a rate-limiting role in iodine transportation (13). For normal human bodies, expression levels of NIS in thyroid tissues are higher than those in other tissues (14). However, it has been hypothesized that due to obstructions to NIS positioning and reductions in NIS protein expression levels, iodine uptake capacities for certain patients with thyroid cancer are reduced or depleted entirely, which may influence the efficacy of I-131 treatment and worsen prognosis (15). By improving functional position expression levels of NIS, iodine uptake capacities of thyroid cancer tissues may be increased (16). Thus, in the present study we investigated whether the cell penetrating peptide of NIS affects the efficacy of I-131 radiotherapy in human thyroid cancer cells. 


\section{Materials and methods}

Cell lines and cell culture. Human thyroid carcinoma TPC-1 cells were purchased from the Cell Bank of Type Culture Collection of Chinese Academy of Sciences (Shanghai, China). TPC-1 cells were maintained in RPMI-1640 medium (Invitrogen; Thermo Fisher Scientific, Inc., Carlsbad, CA, USA) and $10 \%$ fetal bovine serum (Gibco; Thermo Fisher Scientific, Inc., Grand Island, NY, USA), $100 \mathrm{U} / \mathrm{ml}$ penicillin and $50 \mu \mathrm{g} / \mathrm{ml}$ streptomycin (Sigma-Aldrich; Merck KGaA, Darmstadt, Germany), and incubated at $37^{\circ} \mathrm{C}$ in a humidified atmosphere of $5 \% \mathrm{CO}_{2}$.

dTAT nanoparticle (NP)-NIS transfection. dTAT NP-NIS and the negative control (NC) plasmids were purchased from Shanghai GenePharma, Co., Ltd. (Shanghai, China). TPC-1 cells were incubated in six-well plates at a density of $1-2 \times 10^{6}$ cells/well. Subsequently, $100 \mathrm{nmol} / 1$ plasmids were transfected Lipofectamine 2000 (Invitrogen; Thermo Fisher Scientific, Inc.) according to the manufacturer's instructions and transfected into TPC-1 cells.

Reverse transcription-quantitative polymerase chain reaction (RT-qPCR) analysis of dTAT NP-NIS. Following transfection, TPC-1 cells were seeded six-well plates at a density of $1-2 \times 10^{6}$ cells/well for $24 \mathrm{~h}$. Total RNA from the TPC- 1 cells was extracted using TRIzol reagent (Invitrogen; Thermo Fisher Scientific, Inc.). Following treatment with DNase (Takara Biotechnology Co., Ltd., Dalian, China) a TaqMan miRNA Reverse Transcription kit (Applied Biosystems; Thermo Fisher Scientific, Inc., Waltham, MA, USA) was used to synthesize cDNA using $1 \mu \mathrm{g}$ RNA. Subsequently, a 7500 Real-Time PCR system (Applied Biosystems; Thermo Fisher Scientific, Inc.) was used to conduct RT-qPCR using SYBR Premix Ex Taq (Takara Biotechnology Co., Ltd.). The sequences were as follows: NIS forward, 5'-ACSCACTGG AAGCACGGCGG-3' and reverse, 5'-GTGGMRCCGTGC AKRTTGG-3'; $\beta$-actin forward, 5'-AGGCACCAGGGCGTG AT-3' and reverse, 5'-TGCTCCCAGTTGGTGACGAT-3'. The cycling conditions used were $95^{\circ} \mathrm{C}$ for $4 \mathrm{~min}, 95^{\circ} \mathrm{C}$ for $15 \mathrm{sec}$ and $60^{\circ} \mathrm{C}$ for $30 \mathrm{sec}$ for 40 cycles. The RT-qPCR experiment was conducted 6 times. Relative expression of mRNA was quantified using the $2^{-\Delta \Delta \mathrm{CT}}$ method (17).

Western blot analysis. TPC-1 cell total protein was extracted using a radioimmunoprecipitation assay lysis buffer (Sigma-Aldrich; Merck KGaA). Protein concentrations were determined using a Bradford assay (Bio-Rad Laboratories, Inc., Hercules, CA, USA). Equal quantities of total protein $(50 \mu \mathrm{g})$ were resolved using 10-12\% SDS-PAGE (Bio-Rad Laboratories, Inc.) and transferred to polyvinylidene difluoride membranes (Bio-Rad Laboratories, Inc.). The membranes were blocked in 5\% non-fat milk for $2 \mathrm{~h}$ at room temperature and then incubated with rabbit anti-human NIS (1:500; sc-134515), caspase-3 (1:500; sc-98785), Akt (1:200; sc-8312) and phosphorylated-Akt (1:500; sc-33437) and PTEN primary antibodies (1:500; sc-9145; all Santa Cruz Biotechnology, Inc., Santa Cruz, CA, USA) overnight at $4^{\circ} \mathrm{C}$. The membranes were washed with Tris-buffered saline containing Tween 20 (Sigma-Aldrich; Merck KGaA) and then incubated with horseradish peroxidase-conjugated secondary goat anti-rabbit immunoglobulin G antibodies (1:1,000; sc-2922; Santa Cruz Biotechnology, Inc., Santa Cruz, CA, USA) for $1 \mathrm{~h}$ at room temperature. The membranes were visualized using an Immobilon Western chemiluminescent HRP substrate (EMD Millipore, Billerica, CA, USA), and the blots were densitometrically analyzed using Image Lab 3.0 software (Bio-Rad Laboratories, Inc.).

MTT assay. TPC-1 cells were seeded onto 96-well plates at a density of $1-2 \times 10^{3}$ cells/well for 12,24 and $48 \mathrm{~h}$, and subsequently incubated with $20 \mu \mathrm{l}$ MTT $(5 \mathrm{mg} / \mathrm{ml}$; Sigma-Aldrich; Merck KGaA) for $4 \mathrm{~h}$. Then, $150 \mu \mathrm{l}$ DMSO (Invitrogen; Thermo Fisher Scientific, Inc.) was added to each well and shaken for 15 min after the medium was removed. The optical density (OD) of each well was detected at $490 \mathrm{~nm}$ using a microplate reader (BioTek Instruments, Inc., Winooski, VT, USA).

Flow cytometry for evaluation of apoptosis. TPC-1 cells were seeded onto six-well plates at a density of $1-2 \times 10^{6}$ cells/well for $24 \mathrm{~h}$ and washed twice using phosphate-buffered saline (PBS). TPC-1 cells were resuspended using buffer solution (from a FITC Annexin V Apoptosis Detection kit; BD Biosciences, Franklin Lakes, NJ, USA), and incubated with $5 \mu \mathrm{l}$ Annexin V-fluorescein isothiocyanate and $10 \mu \mathrm{l}$ propidium iodide for $30 \mathrm{~min}$ at $4^{\circ} \mathrm{C}$ in the dark. Flow cytometry (FACSCalibur; BD Biosciences) was used to measure cell apoptosis rates of the TPC-1 cells.

DAPI staining assay. TPC-1 cells were seeded onto six-well plates at a density of $1-2 \times 10^{6}$ cells/well for $24 \mathrm{~h}$ and washed twice using PBS. TPC-1 cell was fixed using $4 \%$ paraformaldehyde for $30 \mathrm{~min}$ at $4^{\circ} \mathrm{C}$. Then, fixed TPC-1 cells were washed twice using PBS and incubated with sodium citrate $(0.1 \%)$ containing $0.1 \%$ Triton X-100 (Beyotime Institute of Biotechnology, Haimen, China) for 5 min at $4^{\circ} \mathrm{C}$. TPC-1 cells were dyed by DAPI staining and incubated for $10 \mathrm{~min}$ at $4^{\circ} \mathrm{C}$ in the dark, then activated using ultraviolet. DAPI staining was observed and images captured using a fluorescence microscope (CKX41; Olympus Corporation, Tokyo, Japan) at $340 \mathrm{~nm}$.

Statistical analysis. All values were expressed as the mean \pm standard deviation. Statistical analyses were conducted using SPSS 17.0 software (SPSS, Inc., Chicago, IL, USA). Data were analyzed using the Student's $t$-test. $\mathrm{P}<0.05$ was considered to indicate a statistically significant difference between values.

\section{Results}

Gene expression level of NIS in TPC-1 cells. To evaluate the gene expression of NIS in TPC-1 cells transfected with dTAT NP and negative control, RT-qPCR was performed. As shown in Fig. 1, there was a significant increase in the relative gene expression of NIS of dTAT NP group, compared with the NC group $(\mathrm{P}<0.05)$

Protein expression level of NIS in TPC-1 cells. In order to characterize the dTAT NP-NIS and NC plasmid influence on the protein expression of NIS, western blot analysis was 


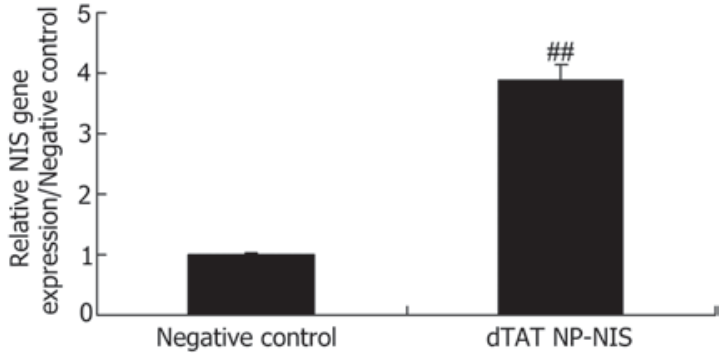

Figure 1. mRNA expression level of NIS in TPC-1 cells. ${ }^{\# /} \mathrm{P}<0.05$ vs. negative control group. NIS, sodium-iodide symporter; dTAT NP, dTAT nanoparticle.

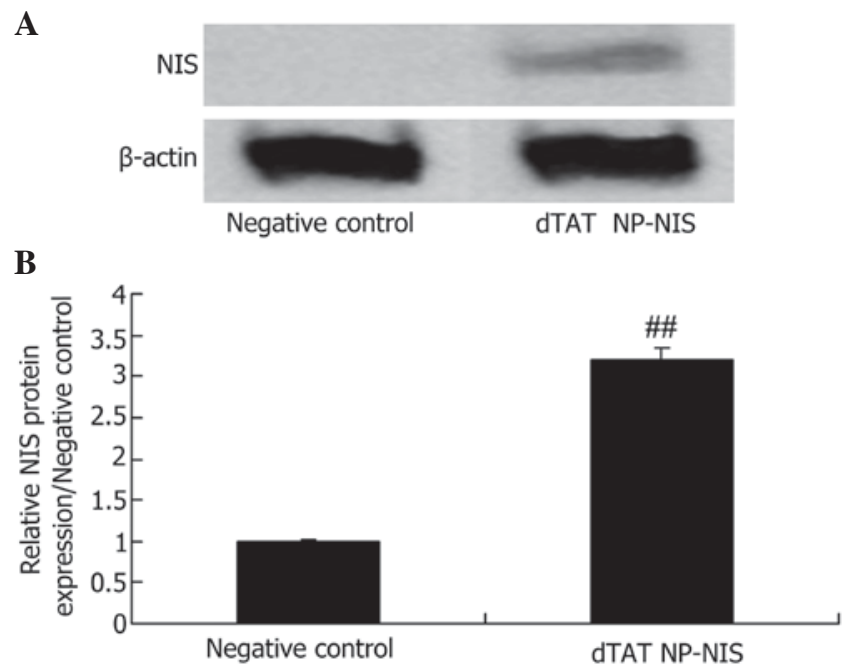

Figure 2. Protein expression level of NIS in TPC-1 cells. (A) Protein expression of NIS was evaluated using western blot analysis. (B) Statistical analysis of NIS protein expression in TPC-1 cells. ${ }^{\# /} \mathrm{P}<0.05$ vs. negative control group. NIS, sodium-iodide symporter; dTAT NP, dTAT nanoparticle.

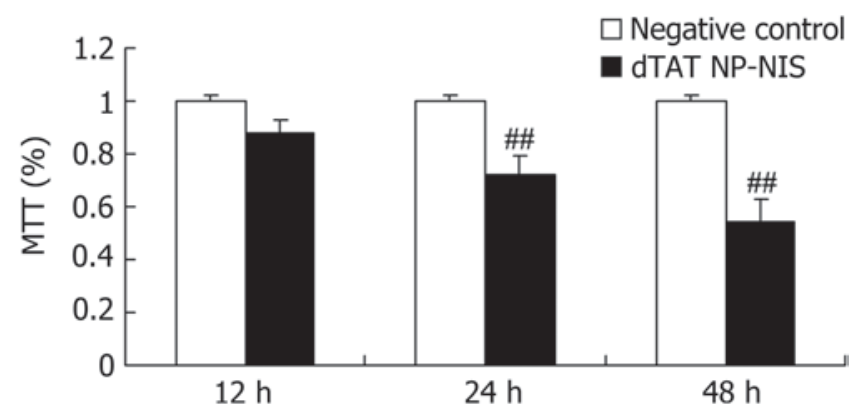

Figure 3. Effect of NIS expression on the cell growth of TPC-1 cells. ${ }^{\# \#} \mathrm{P}<0.05$ vs. negative control group. dTAT NP-NIS, dTAT nanoparticle-sodium-iodide symporter.

performed. The expression of NIS protein was significantly higher than that of the NC group $(\mathrm{P}<0.05$; Fig. 2$)$.

Effect of NIS expression on cell growth in TPC-1 cells. We clarified the overexpression of NIS influence on cell growth of TPC-1 cell. The results from MTT assay showed the cell growth of TPC-1 cell was significantly suppressed after dTAT NP-NIS transfection at 24 and $48 \mathrm{~h}$, compared with the NC group ( $\mathrm{P}<0.05$; Fig. 3).

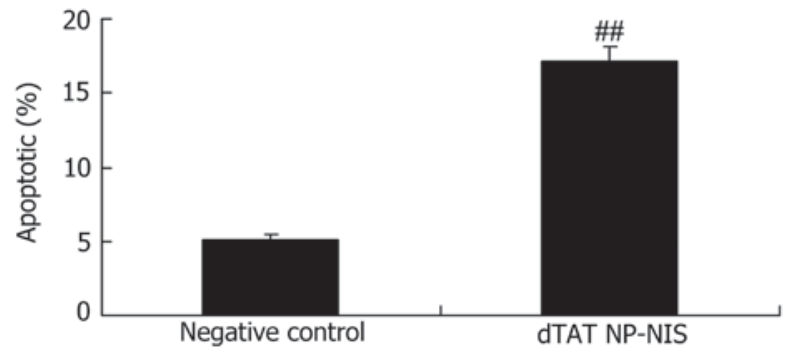

Figure 4. Effect of NIS expression on the apoptosis rate of TPC-1 cells ${ }^{\# \#} \mathrm{P}<0.05$ vs. negative control group. dTAT NP-NIS, dTAT nanoparticle-sodium-iodide symporter.
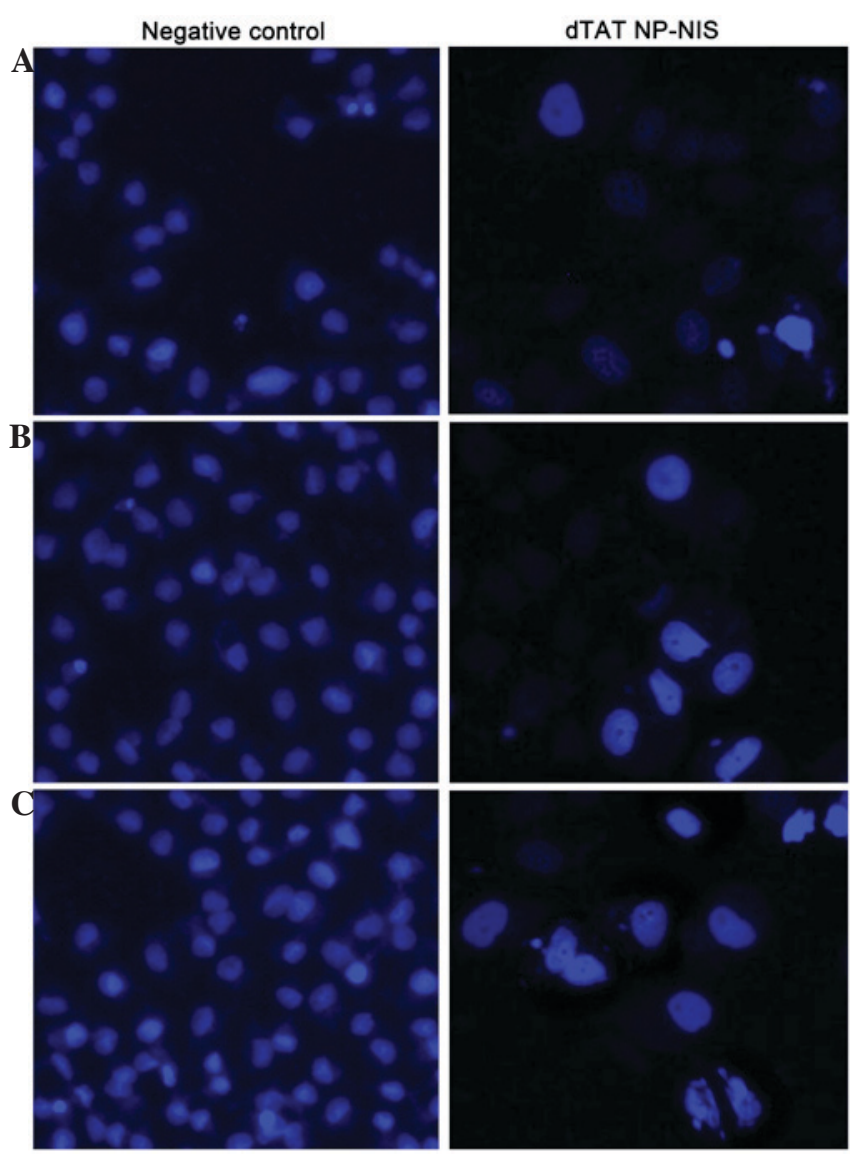

Figure 5. Effect of NIS expression on cell nuclear apoptosis rates of TPC-1 cells at (A) 12, (B) 24 and (C) $48 \mathrm{~h}$ (DAPI staining; magnification, $\mathrm{x} 400) .{ }^{\# \#} \mathrm{P}<0.05$ vs. negative control group. dTAT NP-NIS, dTAT nanoparticle-sodium-iodide symporter.

Effect of NIS expression on apoptosis rates in TPC-1 cells. To determine the effect of the overexpression of NIS apoptosis rates in TPC-1 cells, cellular apoptosis was observed in TPC-1 cells using flow cytometry. As shown in Fig. 4, cellular apoptosis of dTAT NP-NIS transfection was significantly higher than that of the NC group, after dTAT NP-NIS transfection for $24 \mathrm{~h}(\mathrm{P}<0.05)$.

Effect of NIS expression on cell nucleus apoptosis in TPC-1 cells. To validate the overexpression of NIS influence on cell nucleus apoptosis of TPC-1 cell, TPC-1 cells were stained with DAPI. After dTAT NP-NIS transfection at 24 or $48 \mathrm{~h}$, there was a visible increase in the nuclear apoptosis rate of TPC-1 

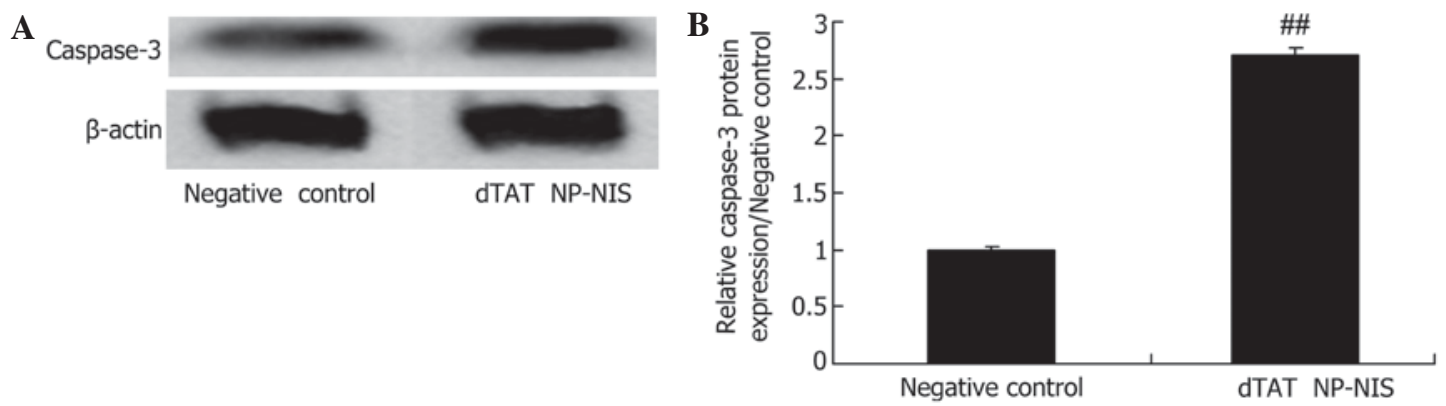

Figure 6. Effect of NIS expression on caspase-3 protein expression of TPC-1 cell. (A) Western blot analysis and (B) statistical analysis of caspase-3 protein expression in TPC-1 cells. ${ }^{\# /} \mathrm{P}<0.05$ vs. negative control group. dTAT NP-NIS, dTAT nanoparticle-sodium-iodide symporter.

$\mathbf{A}$

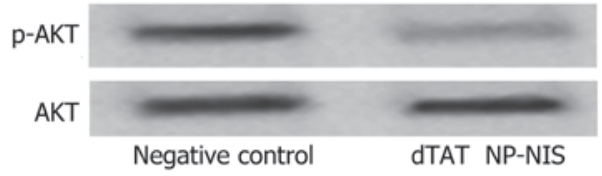

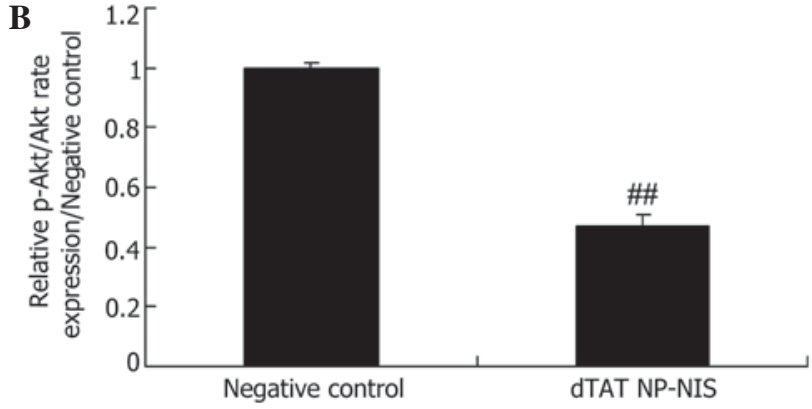

Figure 7. Effect of NIS expression on Akt protein expression of TPC-1 cell. (A) Western blot and (B) statistical analysis of p-Akt/Akt protein expression in TPC-1 cells. ${ }^{\# \#} \mathrm{P}<0.05$ vs. negative control group. dTAT NP-NIS, dTAT nanoparticle-sodium-iodide symporter.

A

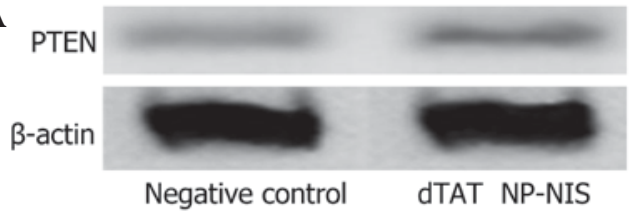

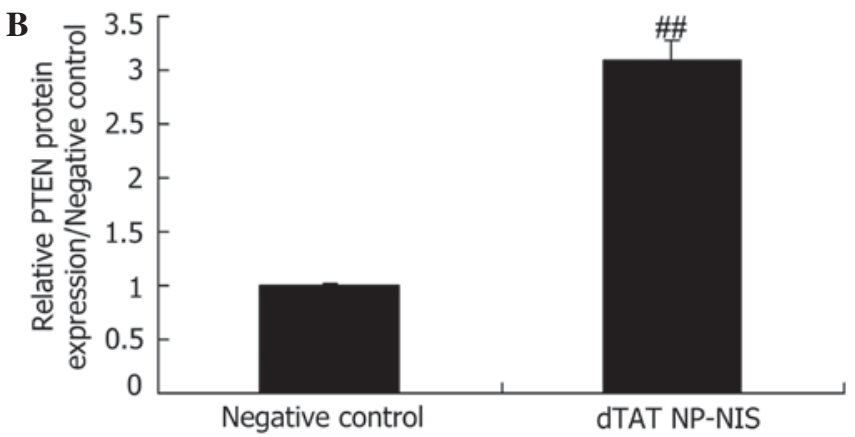

Figure 8. Effect of NIS expression on PTEN protein expression of TPC-1 cell. (A) Western blot and(B) statistical analysis of PTEN protein expression in TPC-1 cells. ${ }^{\# \#} \mathrm{P}<0.05$ vs. negative control group. dTAT NP-NIS, dTAT nanoparticle-sodium-iodide symporter.

cell-transfected with dTAT NP-NIS compared with the NC group (Fig. 5).

Effect of NIS expression on caspase-3 expression in TPC-1 cells. To further clarify whether the effect of NIS expression on caspase- 3 protein expression of TPC-1 cell, caspase- 3 protein expression was analyzed using western blot analysis in TPC-1 cell. Western blot analysis displayed that caspase-3 protein expression was significantly activated in the dTAT NP-NIS transfected cells at $24 \mathrm{~h}$, compared with the NC group (Fig. 6).

Effect of NIS expression on Akt expression in TPC-1 cells. To further validate the effect of NIS expression on Akt signaling in TPC-1 cells, Akt and p-Akt protein expression levels were detected. Compared with the $\mathrm{NC}$ group, the relative Akt/p-Akt rate was significantly reduced by overexpression of NIS (Fig. 7).
Effect of NIS expression on PTEN expression in TPC-1 cells. To further evaluate the effects of NIS expression on PTEN signaling in TPC-1 cells, PTEN protein expression was evaluated. As shown in Fig. 8, relative PTEN protein expression was significantly elevated compared with the NC group (Fig. 8).

\section{Discussion}

Thyroid cancer is among the most common diseases affecting the thyroid. Iodine therapy following surgery may evidently lower recurrence rates (18). However, during the treatment process, sensitivity of tumor nidi or metastatic tumor tissue to iodine is decreased or lost entirely, which may be caused by de-differentiation (19). In cases of the greatest severity with the worst prognosis, methods as surgery, radiotherapy and chemotherapy may not be sufficient to successfully treat PDHC (20). Previous studies have investigated the pathogenesis, therapeutic 
strategies and drug development associated with $\operatorname{PDHC}(16,21)$. The present results showed that dTAT NP-NIS inhibits cell growth and induces cellular apoptosis in TPC-1 cells.

At present, a comprehensive therapeutic method for PTC involves surgery assisted by endocrinotherapy and radioactive I-131 treatment (22). Located on the epithelial cell membrane, NIS is a type of glycoprotein, whose genes are on the short arm of chromosome 19 (23). NIS carries iodine into cytoplasm using a sodium potassium pump, and is important for the maintenance of iodine uptake capacities of thyroids, while also participating in the synthesis of thyroid hormones (24). Furthermore, NIS may be expressed in other locations, such as mammary and prostate glands (25). The present results suggest that the anti-cancer effect of dTAT NP-NIS may be associated with the activation of caspase-3 pathway in TPC-1 cells.

Radioactive I-131 therapy is essential in diagnosis and treatment of ATC and metastasis. The presupposition of the lethal effects of radioactive I-131 to tumor cells is that tumor cells possess increased iodine uptake capacities (26). PTEN/PI3K/AKT signal transduction pathways play an important part in regulating NIS protein synthesis (27). Overactivity of the PTEN/PI3K/AKT signal transduction pathways may affect locations of NIS proteins in cells. The present results suggests that there was significant suppression of PI3K/AKT signaling, which may be associated with the anti-cancer effects of dTAT NP-NIS on TPC-1 cells.

The gene for PTEN protein lie in chromosome 10q23.3 area. PTEN protein is expressed in numerous early embryonic tissues, such as kidney, stomach, central and peripheral nervous system tissue (28). The expression levels of PTEN in the early stage of thyroid tissue growth and in adults are relatively high. In normal human cells, PTEN participates in the regulation of numerous signal transduction pathways, including PTEN/PI3K/AKT, FAK /PI30C and MAPK (28). Through these pathways, PTEN is involved in the maintenance of normal and regulatory substance metabolism and stabilization of the internal environment (29). Low expression levels of PTEN protein in cancer tissues are closely associated with the genesis and progression of tumors (30). The present results suggest that the anti-cancer effects of dTAT NP-NIS increased the protein expression levels of PTEN in TPC-1 cells.

In conclusion, to our knowledge the present study is the first to demonstrate that dTAT NP-NIS inhibits growth and induces the apoptosis of TPC-1 cells, possibly via the caspase- 3 and PTEN/PI3K/AKT pathways. Our data provide a preclinical proof-of-concept for a novel gene delivery system that efficiently delivers NIS to the targeted cancer cells and presents a satisfactory efficacy. This may offer an effective strategy for improving thyroid cancer gene therapy, and warrants further investigation.

\section{Acknowledgements}

This study was partially supported by Guangdong Provincial Natural Science Foundation (grant no. S2013010015733).

\section{References}

1. Iakovou I, Chrisoulidou A, Balaris V, Balaris C, Doumas A and Karatzas N: Acute effects of recombinant human TSH on bone markers in differentiated thyroid cancer. Hell J Nucl Med 13 208-212, 2010.
2. Azizmohammadi Z, Tabei F, Shafiei B, Babaei AA, Jukandan SM, Naghshine R, Javadi H, Nabipour I, Assadi M and Asli IN: A study of the time of hospital discharge of differentiated thyroid cancer patients after receiving iodine-131 for thyroid remnant ablation treatment. Hell J Nucl Med 16: 103-106, 2013.

3. Chen G, Nicula D, Renko K and Derwahl M: Synergistic anti-proliferative effect of metformin and sorafenib on growth of anaplastic thyroid cancer cells and their stem cells. Oncol Rep 33: 1994-2000, 2015

4. Scharpf J, Tuttle M, Wong R, Ridge D, Smith R, Hartl D, Levine R and Randolph G: Comprehensive management of recurrent thyroid cancer: An American Head and Neck Society consensus statement: AHNS consensus statement. Head Neck: Sep 22, 2016 (Epub ahead of print). doi: 10.1002/hed.24513.

5. Waldherr C, Schumacher T, Pless M, Crazzolara A, Maecke HR, Nitzsche EU, Haldemann A and Mueller-Brand J: Radiopeptide transmitted internal irradiation of non-iodophil thyroid cancer and conventionally untreatable medullary thyroid cancer using. Nucl Med Commun 22: 673-678, 2001.

6. Meng S, Wu H, Wang J and Qiu Q: Systematic Analysis of Tyrosine Kinase Inhibitor Response to RET Gatekeeper Mutations in Thyroid Cancer. Mol Inform 35: 495-505, 2016.

7. Rossi ED, Straccia P, Palumbo M, Stigliano E, Revelli L, Lombardi CP, Santeusanio G, Pontecorvi A and Fadda G: Diagnostic and prognostic role of HBME-1, galectin-3 and $\beta$-catenin in poorly differentiated and anaplastic thyroid carcinomas. Appl Immunohistochem Mol Morphol 21: 237-241, 2013.

8. Barkalina N, Jones C, Townley H and Coward K: Functionalization of mesoporous silica nanoparticles with a cell-penetrating peptide to target mammalian sperm in vitro. Nanomedicine (Lond) 10: 1539-1553, 2015.

9. Helmfors H, Eriksson J and Langel Ü: Optimised luciferase assay for cell-penetrating peptide-mediated delivery of short oligonucleotides. Anal Biochem 484: 136-142, 2015.

10. D'Alessio D, Giliberti C, Benassi M and Strigari L: Potential thirdparty radiation exposure from patients undergoing therapy with ${ }^{131} \mathrm{I}$ for thyroid cancer or metastases. Health Phys 108: 319-325, 2015.

11. Gautam A, Chaudhary K, Kumar R, Sharma A, Kapoor P, Tyagi A; Open source drug discovery consortium and Raghava GP: In silico approaches for designing highly effective cell penetrating peptides. J Transl Med 11: 74, 2013.

12. Cazarin JM, Andrade BM and Carvalho DP: AMP-activated protein kinase activation leads to lysome-mediated $\mathrm{NA}(+) / \mathrm{I}(-)$-symporter protein degradation in rat thyroid cells. Horm Metab Res 46: 313-317, 2014

13. Merron A, Peerlinck I, Martin-Duque P, Burnet J, Quintanilla M, Mather S, Hingorani M, Harrington K, Iggo R and Vassaux G: SPECT/CT imaging of oncolytic adenovirus propagation in tumours in vivo using the $\mathrm{Na} / \mathrm{I}$ symporter as a reporter gene. Gene Ther 14: 1731-1738, 2007.

14. Kurebayashi J, Tanaka K, Otsuki T, Moriya T, Kunisue H, Uno M and Sonoo H: All-trans-retinoic acid modulates expression levels of thyroglobulin and cytokines in a new human poorly differentiated papillary thyroid carcinoma cell line, KTC-1. J Clin Endocrinol Metab 85: 2889-2896, 2000.

15. Modoni S, Landriscina M, Fabiano A, Fersini A, Urbano N, Ambrosi A and Cignarelli M: Reinduction of cell differentiation and 131I uptake in a poorly differentiated thyroid tumor in response to the reverse transcriptase (RT) inhibitor nevirapine. Cancer Biother Radiopharm 22: 289-295, 2007.

16. Said M, Fujimoto M, Franken C, Woo S, Vuong B and Haigh PI: Preferential use of total thyroidectomy without prophylactic central lymph node dissection for early-stage papillary thyroid cancer: Oncologic outcomes in an integrated health plan. Perm J 20: 15-251; 2016.

17. Livak KJ and Schmittgen TD: Analysis of relative gene expression data using real-time quantitative PCR and the 2(-Delta Delta $\mathrm{C}(\mathrm{T})$ ) Method. Methods 25: 402-408, 2001.

18. Kist JW, de Keizer B, Stokkel MP, Hoekstra OS and Vogel WV; THYROPET study group: Recurrent differentiated thyroid cancer: Towards personalized treatment based on evaluation of tumor characteristics with PET (THYROPET Study): Study protocol of a multicenter observational cohort study. BMC Cancer 14: 405, 2014.

19. Kundu P, Lata S, Sharma P, Singh H, Malhotra A and Bal C: Prospective evaluation of (68)Ga-DOTANOC PET-CT in differentiated thyroid cancer patients with raised thyroglobulin and negative (131)I-whole body scan: Comparison with (18)F-FDG PET-CT. Eur J Nucl Med Mol Imaging 41: 1354-1362, 2014. 
20. Ghofrani M, Sosa JA, Ocal IT and Angeletti C: Fine needle aspiration of poorly differentiated oxyphilic (Hurthle cell) thyroid carcinoma: A case report. Acta Cytol 50: 560-562, 2006.

21. Sherman SI, Clary DO, Elisei R, Schlumberger MJ, Cohen EE, Schöffski P, Wirth LJ, Mangeshkar M, Aftab DT and Brose MS8: Correlative analyses of RET and RAS mutations in a phase 3 trial of cabozantinib in patients with progressive, metastatic medullary thyroid cancer. Cancer: Aug 15, 2016 (Epub ahead of press). doi: $10.1002 / \mathrm{cncr} .30252$.

22. Liepe K: Sensitivity of preparation with rhTSH or thyroid hormone withdrawal using ${ }^{131}$ I-whole body scans to identify metastases of differentiated thyroid cancer. Int J Surg 16: 107-112, 2015.

23. Vilasdechanon N, Ua-Apisitwong S, Chatnampet K, Ekmahachai M and Vilasdechanon J: Design of patient rooms and automatic radioiodine-131 waste water management system for a thyroid cancer treatment ward: 'Suandok Model'. J Radiol Prot 34: 699-708, 2014.

24. Turba UC, Sildiroglu O and Rehm PK: Radioiodine (131I) accumulation in bronchogenic cyst in the setting of thyroid carcinoma remission. Clin Imaging 36: 224-227, 2012.

25. Bastos AU, Oler G, Nozima BH, Moyses RA and Cerutti JM: BRAF V600E and decreased NIS and TPO expression are associated with aggressiveness of a subgroup of papillary thyroid microcarcinoma. Eur J Endocrinol 173: 525-540, 2015.
26. D'Alessio D, Giliberti C, Benassi M and Strigari L: Potential third-party radiation exposure from patients undergoing therapy with 131I for thyroid cancer or metastases. Health Phys 108: 319-325, 2015.

27. de la Chapelle A and Jazdzewski K: MicroRNAs in thyroid cancer. J Clin Endocrinol Metab 96: 3326-3336, 2011.

28. Duman BB, Kara OI, Uğuz A and Ates BT: Evaluation of PTEN, PI3K, MTOR and KRAS expression and their clinical and prognostic relevance to differentiated thyroid carcinoma. Contemp Oncol (Pozn) 18: 234-240, 2014.

29. Yun F, Jia Y, Li X, Yuan L, Sun Q, Yu H, Shi L and Yuan H: Clinicopathological significance of PTEN and PI3K/AKT signal transduction pathway in non-small cell lung cancer. Int J Clin Exp Pathol 6: 2112-2120, 2013

30. Biswas R, Mondal A and Ahn JC: Deregulation of EGFR/PI3K and activation of PTEN by photodynamic therapy combined with carboplatin in human anaplastic thyroid cancer cells and xenograft tumors in nude mice. J Photochem Photobiol B 148: 118-127, 2015. 